\title{
What motivates patients to become involved in postgraduate medical training in a family planning clinic?
}

\author{
Jennifer Heathcote
}

\begin{abstract}
Objectives To discover what motivates patients who agree to doctors on postgraduate clinical training attachments being involved in their care; to explore potential negative effects on patients; and to consider how the experience could be improved for the patient.
\end{abstract}

Methods Questionnaire survey of 103 female family planning clinic (FPC) patients. Patients were recruited from the waiting room of a community FPC.

Results Motivation could be classified into three categories: $84 \%$ of patients gave altruistic reasons for agreeing to see training doctors, $59 \%$ indicated the possibility of personal gain and $49 \%$ felt some degree of obligation. Potential disadvantages to seeing training doctors included marginalisation of patient care, strain on the doctor-patient relationship, and exposure to potential discomfort or harm. The experience could be improved by involving patients more in the teaching process.

Discussion and conclusions Patients were motivated to become involved in training for a variety of reasons, mainly altruism, personal gain or a sense of obligation. There is evidence that patients may not be fully aware of the potential disadvantages of seeing a training doctor. Patients may benefit from being given more choice about their level of involvement to enable them to give informed consent before seeing a training doctor. Patients should feel comfortable about saying no. There is potential to develop the teaching role of some of the most motivated patients.

Keywords DFSRH, patient consent, patient motivation, postgraduate training, recruitment

J Fam Plann Reprod Health Care 2008; 34(2): 103-106 (Accepted 8 July 2007)

\section{Introduction}

Clinical experience is a vital part of medical training, but we should not assume that all patients are willing to be involved in this. Understanding what motivates patients to agree to play a part in medical education could have a positive influence on the way they are asked, and make the experience more rewarding for the patient.

Patient motivation for involvement in medical student education has been described in some detail by Lynöe $e t$ al. ${ }^{1}$ but there is little research into the experiences of patients with postgraduate medical training. Diploma of the Faculty of Sexual and Reproductive Healthcare (DFSRH) [formerly Diploma of the Faculty of Family Planning and Reproductive Health Care (DFFP)] training doctors are post-registration doctors, mainly general practice registrars or gynaecology senior house officers, who attend family planning clinics (FPCs) to gain clinical experience towards their diploma. This study sought the views and experiences of patients attending a community FPC that frequently has DFSRH training doctors in attendance. Depending on their level of experience, these doctors may observe or lead consultations in the presence of a more senior member of staff, or see patients on their own, under supervision of a Faculty instructing doctor. Practical procedures such as intrauterine device (IUD) and implant insertions would always be performed in the presence of an experienced doctor.

\section{Methods}

The study methodology was as described in the first article in this series. ${ }^{2}$

Central and Eastern Cheshire Primary Care Trust, Family Planning Clinic, Waters Green Medical Centre,

Macclesfield, UK

Jennifer A Heathcote, MA, FFSRH, Staff Grade

Correspondence to: Dr Jennifer Heathcote, Family Planning Clinic, Waters Green Medical Centre, 1st Floor, Sunderland Street, Macclesfield, Cheshire SK11 3TL, UK.

E-mail: drjennyheathcote@hotmail.com

\section{Key message points}

- Patients are motivated by a sense of altruism, the potential for personal gain and a feeling of obligation.

- There are potential disadvantages of seeing training doctors, and patients are not always made aware of this fact.

- The role of patients in postgraduate medical training could be extended to benefit both doctors and patients.

\section{Ethical approval}

Ethical approval for the study was granted by the Cheshire Local Research Ethics Committee.

\section{Results and discussion}

Six patients preferred not to take part in the study when approached by the receptionist. A total of 103 questionnaires were issued and all were returned; four patients said that they would not want to be seen by a training doctor and did not answer any further questions; 89 patients said that they wouldn't mind seeing a training doctor and 10 were undecided or not sure. Twenty-seven patients remembered seeing a training doctor at a previous consultation, of whom 26 would be willing to see a training doctor again and one was not sure. Patient comments have been quoted verbatim.

The FPC in this study serves a population that has quite distinctive characteristics: it includes few individuals from ethnic minority groups, being over $98 \%$ white, ${ }^{3}$ and the general level of education is high $(28.4 \%$ are educated to degree level or beyond compared to the national average of $19.8 \%$ ). This may reduce the level of generalisability of the results.

What reasons do patients give for allowing training doctor involvement?

Patients' reasons for agreeing to allow DFSRH training doctors to be involved in their care could be categorised under three main headings. 


\section{Obligation}

The DFSRH practical training translates sexual health theory into clinical practice; patient participation is implicit. Some questionnaire respondents $(9 \%)$ thought that patients should expect to see doctors who are training without being asked, but the majority felt that patients should be asked.

Society expects doctors to be adequately trained, and the General Medical Council ${ }^{4}$ puts the obligation on each doctor to meet those expectations. Does the training doctor therefore have the right to expect patients to agree to see them? Doctors holding a DFSRH are expected to have reached a defined level of knowledge and competence. Ubel et al. ${ }^{5}$ suggest that the societal need to educate future doctors may place moral limits on patients' rights to refuse to interact with medical students. A minority of FPC patients $(12 \%)$ said that they would "find it very hard to say no" if asked to help with doctor training. Half (49\%) of the respondents agreed with at least one statement that suggested a sense of obligation (Box 1).

Waterbury 6 insisted that there should be a clear statement of a patient's right to refuse and wrote: "a decision based on a perceived obligation is coercion, not informed consent". If patients would find it very hard to refuse, current practice may not be placing sufficient emphasis on the patients' right to opt out. He critically analysed the arguments for patient obligation to participate in medical student education and identified four main categories, all of which he refuted. The categories and arguments Waterbury proposed with regard to medical students could be applied to postgraduate medical training:

- Furthering of medical education - a social obligation.

- Compensation when patients were uninsured or unable to pay (not relevant in this country in a National Health Service setting).

- An equitable return for the care received in a teaching hospital where patients believe they get better care. [NB. Macclesfield FPC is not part of a teaching hospital, but the same principle may apply here if patients perceive the instructing doctors to be more senior or experienced.]

- Fulfilment of a student's need for (and some would say right to) clinical training.

The training doctor and clinic may also have obligations: the DFSRH training doctor is obliged to see sufficient patients to achieve the diploma level of competence, and the training clinic and instructing doctor who have received payment from the training doctor may also be under an obligation to provide the necessary practical training which includes access to patients.

Box 1: Categorisation of replies to Question 23 (There are many reasons why people might agree to help with doctor training. Please tick as many of the following that apply to you.)

Replies categorised as 'obligation'

- I would find it hard to say no

- I owe it to the NHS to help with doctor training

- I would do it out of loyalty to the clinic staff

Reply categorised as 'altruistic'

- I want to help the training doctor

Replies categorised as 'perceived personal benefit'

- I might learn something more than I would have done at my usual clinic appointment

- I might be seen more quickly

- I might get better treatment

\section{Altruism}

When patients were asked to give reasons for agreeing to help with doctor training $84 \%$ agreed with the statement: "I want to help the training doctor". Of the patients who had seen a training doctor, 16/27 said that they liked to feel that they had helped someone.

This compares with other studies looking at patient involvement in the training of medical students; in Lynöe $e t$ al. ${ }^{1} 88 \%$ of patients were altruistically motivated, Chipp et $a l .{ }^{7}$ found $61 \%$ and Magrane et al. ${ }^{8} 73 \%$.

FPC patients commented:

"I would feel happy to see a doctor in training as this would help with their career as it would give them greater experience.” (Patient 24)

"It is much better for a new doctor to come into work after having had experience with a trained doctor rather than coming straight from university. It is an excellent way of getting to know the way the job works." (Patient 67)

\section{Perceived personal benefit}

More than half $(59 \%)$ the patients in this study indicated at least one possible personal benefit of agreeing to see a training doctor (Box 1). Research on medical student education by Lynöe et al. ${ }^{1}$ demonstrated that $12 \%$ of patients perceived some personal benefit, and Chipp et al. ${ }^{7}$ found this percentage to be $11 \%$. The higher levels reported in the present study may be a reflection of the questionnaire design; patients were given a greater number of options to tick than in either of the other studies. It may also be because DFSRH training doctors are more qualified and thus more likely to make a valuable contribution to patient care. Perceived benefits might include:

1. The possibility of learning more from the consultation than usual. This was cited as a reason for agreeing to see a training doctor by $51 \%$ of respondents $(4 / 27$ patients who had seen a training doctor felt this was their experience).

In a study in general practice by O'Flynn et al. ${ }^{9}$ looking at patient attitudes to medical students being present during consultations, about one quarter of patients did not want the doctor to discuss their case after they had left the room. Since this type of discussion is integral to the student's learning during teaching consultations, the authors question whether it is appropriate to explain these aspects of teaching to patients before they consent to seeing students. Current practice may not make this explicit; when asked whether they would prefer to listen to the training doctor and instructing doctor discussing their case $68 \%$ said that they would prefer to hear what was said, $30 \%$ didn't mind and only $2 \%$ would rather not know what was said. [Of patients who had previously seen a training doctor, this changed to $81 \%(22 / 27)$ preferring to listen, with only one patient preferring not to, and the others did not express any preference.] No patient felt that they had learned more than they would have liked.

2. Being seen more quickly. This was cited as a reason by $16 \%$ of respondents.

"Feel strongly that by introducing training doctors into system - this may help to provide a faster appointment system." (Patient 62)

This is probably a misplaced belief in this clinic since there is no provision for extra time or staff when training doctors are present, and patients are seen in turn either with or without the training doctor as preferred. Benson et al.'s patients gave the increased length of teaching consultations as the main disadvantage of seeing students. ${ }^{10}$

3. Getting better treatment. A number of patients (9\%) felt that seeing a training doctor resulted in better treatment. In 
this clinic a training doctor is always under the supervision of one of the more experienced instructing doctors but this does not necessarily imply better treatment, and there may be other reasons.

"When I saw a training doctor I found it quite reassuring. Although I wasn't told how much experience the training doctor had it felt as though I was getting a 'second opinion'." (Patient 56)

4. Future personal benefit from having well-trained doctors. Certain comments made by respondents indicated that this might be perceived as a benefit of agreeing to see a training doctor.

"Doctors need to train sometime. No training - no doctors - no clinic!" (Patient 85)

"I would be more than happy to help out a training doctor, I don't feel this would cause any embarrassment as there is every chance that this person would be treating me one day as a qualified doctor." (Patient 86)

Grant's 11 study offered five reasons why patients agreed to see medical students that may be relevant in postgraduate training:

- Patients enjoyed the additional attention.

- Potential for review of their case in depth.

- An opportunity to reveal and discuss worrying problems.

- Previously overlooked signs or symptoms may be revealed.

- A way of paying back the kindnesses received.

\section{Could involvement in training harm the patient?}

There may be disadvantages to seeing training doctors: consultations might take longer or be more difficult to understand, or training doctors may be clumsier in a practical procedure compared to an experienced doctor. Waterbury 6 identified three areas of concern:

1. Marginalisation of patient care. The process of teaching may subsume the process of treatment. Two patients (7\% of those who had seen a training doctor) felt that they had been ignored while the training and instructing doctors talked about them.

2. Strain on the patient-doctor relationship. In a study looking at medical students in general practice, O'Flynn et al. ${ }^{12}$ reported that $10 \%$ of patients had left a general practitioner consultation where there was a medical student present without saying all they had wanted to say. One FPC patient had wanted to say more but felt that they didn't have the opportunity. Another patient in this study made the following comment:

"On the occasion I have been seen by a training doctor, I was at the GP surgery and hadn't been told there would be anyone in the room. I had gone about a personal problem and actually made up another minor reason for going. It was a big shock to find someone else in the room." (Patient 31)

3. Exposure to potential harm and discomfort. Supervision minimises the increased risk of treatment from an inexperienced doctor, but cannot completely compensate for discomfort or patient anxiety. Despite this, Lynöe et al. ${ }^{1}$ observed that "many patients appear to have a great deal of forbearance with and patience for various forms of encroachment". He found that $88 \%$ of patients were in principle positive to participating in clinical teaching of medical students despite one-third reporting negative past experiences.

In the present study one patient felt more embarrassed than usual, although none felt that they had been treated less well than previously. The issue of supervision was considered very important.

"I completely support doctor training, however, I would only be confident if all the decisions were supervised, especially if medicines are prescribed and/or examinations." (Patient 60)

The presence of an instructing doctor does not remove an element of risk, particularly when a procedure is being performed. This would be particularly relevant, for example, when IUD fitting is being learned, since inexperienced doctors have three times more failed fittings than experienced doctors. ${ }^{13}$ This point was not understood by all of the patients as the following comments demonstrate.

"If the training doctor is with a qualified doctor there is no risk of anything going wrong. It gives training doctors a chance to learn more and practise on the 'real' thing." (Patient 67)

"I wouldn't mind [the training doctor fitting an IUD] as long as a doctor was there to check everything was going right." (Patient 79)

"I am all for helping training doctor doctors as practical experience is best, as long as they are overseen by a trained doctor to avoid errors." (Patient 91)

Patients need to be aware of the potential drawbacks of involvement in training if they are to give fully informed consent.

\section{How might patient motivation be increased?}

Traditionally patients have had a passive role in medical education, but recently they have been encouraged to be more involved. Stacy and Spencer ${ }^{14}$ reported that patients see themselves as having specific contributions to make to medical students' education and training, as experts and exemplars of their condition, and as facilitators in the development of students' professional skills and attitudes.

Wykurz and Kelly ${ }^{15}$ reviewed the literature in this area, drawing from sources where the patient or carer were 'active' teachers, facilitating learning and assessing the acquisition of knowledge, skills and attitudes associated with medical practice. They concluded that involving patients as teachers has important educational benefits for the learners, and that the patients enjoyed their role. FPC 'patients' do not see themselves as patients, being generally fit and healthy, and the training doctors are qualified doctors, but it is worth considering ways in which users of specific contraceptive methods, for example, could be involved in a teaching role.

Howe and Anderson 16 found that the patients' experience was improved when their feedback was valued. One patient in this study agreed with the statement: "I would like to have been asked my views on the way the training doctor treated me". This is an aspect of patient involvement that might be considered; it would be particularly relevant in cases where a consultation had taken place without the instructing doctor being present. Patient feedback could also provide triangulation when the instructing doctor is present.

Some patients may be given training to take on more formal roles as educators. Gynaecology teaching associates have been trained to teach gynaecological examination to medical students with some success. ${ }^{17}$ An area of particular interest to family planning would be the teaching of diaphragm fitting. Two patients (both nurses with family 
planning experience) have recently spontaneously volunteered to come in as 'live models' when they realised that we often experience problems providing training doctors with practical experience of this method. A feasibility study seeking the views of professional patients who taught diaphragm fitting to DFSRH training doctors was described by Pickard et al. ${ }^{18}$ This was expensive, however, and our enthusiastic and knowledgeable volunteers could more than fulfil our training requirements.

Waterbury 6 felt that the widespread sense of altruism amongst patients could be further increased if more patients realised the value of medical education. He suggested that patient leaflets explaining this point should be left in waiting rooms.

Spencer et al ${ }^{19}$ describe the Cambridge framework, a tool for evaluating the involvement of patients in the educational process; this could be used by curriculum planners and teachers to review and monitor patient involvement. The Royal College of Physicians has a Patient Involvement Unit, with lay members, which is consulted about training. ${ }^{20}$

\section{Conclusions}

DFSRH training would be impossible without the goodwill of patients and this research suggests that patients are willing to become involved: $96 \%$ of patients in this study were willing to consider seeing a training doctor. Previous experience did not diminish this: $26 / 27$ patients who had seen a training doctor in the past were willing to see one again.

Patients are motivated by a varying combination of obligation, altruism and a belief that they will benefit personally, altruism being the most commonly expressed motive. This research has demonstrated that although many patients are motivated to become involved, some are unsure, and it is important that they do not feel coerced into agreeing to see a training doctor. Some patients find it difficult to say no when asked, and we need to be sensitive to this. Patient involvement should be an active process of 'opting in'; patients' decision-making is empowered by the provision of appropriate information about their role. It must be made clear that they are under no obligation to see training doctors, and that their care will not be adversely affected if they choose not to see a training doctor. Patients should be made aware of potential disadvantages to being involved in doctor training.

This research has suggested some ways to enhance the training experience for the patient; for example, patients may wish to be involved in deciding whether to be present during any discussion of their case between the instructing and training doctors. They might also be encouraged to become more active educators by giving feedback to training doctors, or being trained as 'expert patients' with a more formal educational role.

The patient population of this clinic may have unusual demographic characteristics, and further research is indicated in different settings to provide information that could be used in the production of guidelines for the process of patient consent to involvement in postgraduate medical education. It would be interesting to know whether there are any existing guidelines or examples of good practice in this field.
Statements on funding and competing interests

Funding The author received a research grant from the North West Society of Sexual Medicine and Family Planning. The research was, however, undertaken independently of this organisation.

Competing interests None identified.

\section{Author's note}

This article formed part of a dissertation for an MA in Clinical Education at Edge Hill College, University of Lancaster, UK.

\section{References}

1 Lynöe N, Sandlund M, Westberg K, Duchek M. Informed consent in clinical training - patient experiences and motives for participating. Med Educ 1998; 32: 465-471.

2 Heathcote J. Postgraduate medical training: getting patients on board. J Fam Plann Reprod Health Care 2007; 33: 267-270.

3 Office for National Statistics. National Census, 2001. Neighbourhood statistics for Macclesfield (Local Authority). http://www.neighbourhood.statistics.gov.uk/dissemination/Lead KeyFigures. do $? a=3 \& b=276900 \& c=S K 9+5 D W \& d=13 \& e=15 \& g$ $=429156 \& \mathrm{i}=1001 \times 1003 \times 1004 \& \mathrm{~m}=0 \& \mathrm{r}=0 \& \mathrm{~s}=1193706679904 \&$ enc $=1$ [Accessed 5 May 2007].

4 General Medical Council. The duties of a doctor registered with the General Medical Council. 2006. http://www.gmc-uk.org/ guidance/good medical practice/duties_of_a doctor.asp [Accessed 5 May 2007]

5 Ubel P, Silver-Isenstadt A. Are patients willing to participate in medical education? J Med Ethics 2000; 11: 230-235.

6 Waterbury J. Refuting patients' obligations to clinical training: a critical analysis of the arguments for an obligation of patients to participate in the clinical education of medical students. Med Educ 2001; 35: 286-294.

7 Chipp E, Stoneley S, Cooper K. Clinical placements for medical students: factors affecting patients' involvement in medical education Med Teach 2004; 26: 114-119.

8 Magrane D, Gannon J, Millet C. Obstetric patients who select and those who refuse medical students' participation in their care. Acad Med 1994; 69: 1004-1006.

9 O'Flynn N, Spencer J, Jones R. Consent and confidentiality in teaching in general practice: survey of patients' views on presence of students BMJ 1997; 315: 1142.

10 Benson J, Quince T, Hibble A, Fanshawe T, Emery J. Impact on patients of expanded, general practice based, student teaching: observational and qualitative study BMJ 2005; 331: 89-92.

11 Grant V. Patient involvement in clinical teaching. J Med Ethics 1994; 20: 244-250.

12 O'Flynn N, Spencer J, Jones R. Does teaching during a general practice consultation affect patient care? $\mathrm{Br} J$ Gen Pract 1999; 49: 7-9.

13 Farmer M, Webb A. Intrauterine device insertion-related complications: can they be predicted? J Fam Plann Reprod Health Care 2003; 29(4): 227-231.

14 Stacy R, Spencer J. Patients as teachers: a qualitative study of patients' views on their role in a community-based undergraduate project. Med Educ 1999; 33: 688-694.

15 Wykurz G, Kelly D. Developing the role of patients as teachers: literature review BMJ 2002; 325: 818-821.

16 Howe A, Anderson J. Involving patients in medical education. BMJ 2003; 327: 326-329.

17 Pickard S, Baraitser P, Rymer J, Piper J. Can gynaecology teaching associates provide high quality effective training for medical students in the United Kingdom? Comparative study. BMJ 2003; 327: 1389-1392.

18 Pickard S, Baraitser P, Herns S, Massil H. Fitting contraceptive diaphragms: can laywomen provide quality training for doctors? $J$ Fam Plann Reprod Health Care 2001; 27: 131-134.

19 Spencer J, Blackmore D, Heard S, McCrorie P, McHaffie D, Scherpbier A, et al. Patient-oriented learning: a review of the role of the patient in the education of medical students Med Educ 2000; 34: 851-857.

20 Royal College of Physicians. Patient Involvement Unit. http://www.rcplondon.ac.uk/college/piu/index.asp [Accessed 5 May 2007]. 